\title{
Subject Allocation to Teacher Trainers in Cameroon: Conflicts and Perspectives
}

\author{
Patrick Kongnyuy ${ }^{1}$ Henri Rodrigue Njengoué Ngamaleu ${ }^{2} \quad$ Mboh Jones Nchenepoh $^{2}$ \\ 1.Associate Professor, Educational Administration and Planning, University of Bamenda, Cameroon PO Box 39 \\ Bambili \\ 2.Associate Professor, Social Psychology, University of Yaoundé 1, Cameroon \\ 3.PhD Research Fellow, Curriculum Development and Evaluation, University of Yaoundé 1, Cameroon
}

\begin{abstract}
This study was concerned with the allocation of teacher trainers to subjects at the teacher training colleges in Cameroon. The case of some selected Government Teacher Training Colleges. This study was designed to find out the extent to which every teacher trainer can effectively teach every subject of the Grade one teacher training programme if assigned to do so. The Deans of study have to allocate subjects to teacher trainers based on needs while considering the academic backgrounds of the teachers. Most often than not, these teachers happen to have similar academic backgrounds. This results into a situation whereby, some subjects such as statistics and ICT are resisted or turned down by some teacher trainers when assigned to teach them. This situation often escalates into a teacher trainer/Dean of studies conflicts which hamper the smooth functioning of the colleges. This paper evokes the root cause of such conflicts and proposes the way forward. The following hypotheses guided the study. Ho: Subject allocation does not significantly influence work climate at the teacher training colleges. Ha: Subject allocation significantly influences work climate at the teacher training colleges. The cross-sectional survey research design that employed the descriptive approach was adopted for the study. Specifically, forty (40) participants were randomly selected from a population of about 116 teacher trainers. The Scientific Management Theory as postulated by Taylor (1909) formed the study's theoretical framework. Data analysis was done using both descriptive statistics and inferential statistic with the help of the Statistical Package for the Social Sciences (SPSS) version 26. The findings from the analysis revealed that the teacher trainers could effectively teach $29.6 \%$ of the 27 subjects of the teacher training programme. None of them indicated that they can effectively teach all the subjects of the Grade one Teacher Training Programme. The study recommended that, in order to do away with teacher trainer/Dean of Study conflicts and boost teacher trainers' output, the admission requirements at the Department of Sciences of Education at the HTTCs in Cameroon need to be revised.
\end{abstract}

Keywords: Subject allocation, Teacher Trainer, Conflicts, Perspectives

DOI: $10.7176 / \mathrm{JEP} / 12-24-07$

Publication date:August $31^{\text {st }} 2021$

\subsection{Introduction}

Educational reform in contemporary Cameroon has failed to develop desirable attitudes upon which a progressive nation-state can be built. The failure to structure education to respond to national goals has encouraged the perpetuation of the inherited colonial education systems which are culturally and economically unsuitable and which have remained largely unchanged. The failure to reform education has affected not just the peoples' attitudes to economic survival but has had significant ramifications for the consolidation of national integration and the development of national identity. Western education, which was introduced in Cameroon in 1844 by the British Baptist Missionary Society (B.M.S.), was strengthened during the colonial period by a joint effort of colonial Governments and Missionary societies. Different colonial Governments and Missionary societies applied diverse approaches to the development of education as a result of divergent attitudes and perceptions to education. The confusion introduced by these conflicting approaches imbued Cameroonians with attitudes that today hamper efforts to re-structure Cameroon education. Since independence, some African Governments, such as Tanzania (1967), Nigeria (1985) and Kenya (1985) have attempted to reform (Africanise) their educational systems to suit national demands by adapting education to African conditions. But others such as Cameroon have failed to adapt the educational systems, as several attempts to contextualize Education has been very challenging partly due to the multiethnic nature of Cameroon.

In Cameroon, two distinct educational systems inherited from the French and the British colonial regimes still survive, despite several attempts to unify and harmonise them into a single system responsive to national needs. There are also internal difficulties in attempts to make the respective inherited systems more responsive to Cameroon needs. In 1962 and 1963, laws were passed reorganising the educational systems. But these laws were never implemented. A series of seminars on the reform of education were also held. The first in March 1973, focused on primary education. It was sponsored by UNESCO and other multilateral and bilateral funding agencies. The second was in December 1974, involving a one week session of the Council for Higher Education and Scientific and Technical Research. The third was in April 1977. The objective of the reform was to apply the 
notions of "functionalism" and "practicality" to the whole educational system and therefore adapt education to the economic or production system of the nation. The reform aimed to harmonise the two inherited systems of education; to replace a less profitable literary aspect of education with practical content adaptable to the Cameroonian milieu; and to evolve an educational system that would enhance the acquisition of skills to ensure the possibility for students to earn an independent livelihood rather than wait for state employment. For this dream to be realised, there is need to ensure that teachers are well equipped to play their role of scaffolding learners optimally. The quality of learners to be groomed has a direct bearing on the qualities of teachers that have been trained. (Tosam, 1988).

\subsection{Background and the Problem}

Teacher education in pre-independent Cameroon started in the Anglophone zone in 1923 through a school-based teacher training course and the Francophone zone in 1925. First School Leaving Certificate (FSLC) was a prerequisite and success in the official competitive exam were entry requirements into the three year Grade III certificate course whose first batch graduated in 1933. After three years training, successful candidates were permitted to teach for one year or so before proceeding to another two year Grade II training Course. For the Anglophones, this phase of training was offered only in Nigeria, then British colony to which Anglophone Cameroon was administered as part of a mandated territory. However, some candidates took four straight years to cover the entire grade III and Grade II course levels when it was later launched in Cameroon.

A further development in teacher education programme was when the Grade II level was instituted in Government Teachers' Training College (GTTC) in Cameroon in 1945. Nonetheless, because of lack of resources like qualified teacher trainers, materials and finance, the training programmes were temporary closed down between 1947 and 1950. When training activities were resumed later, all the three grade levels: III, II and I were offered and jointly run by the colonial government, private missionary bodies and Non-Governmental Organisations (NGOs). In the Francophone part of Cameroon, such endeavour was predominantly managed by the private agencies (Tchombe, 1997, 1998, 2000; Tchombe and Agbor, 2005). In the post-independent era, that is, after 1960, the pre-independent institutionalised education system has been maintained with a series of management and organisational reforms. One of the latest reforms that took place in teacher education was in 2011. Here the Ministry of Basic Education ordered a diagnostic study into the teacher training programme in Cameroon. This study was conducted by Marguirete, 2011 of the French Institute of Educational Research. She came out with the some recommendations. It should be noted that this recommendations are yet to be fully implemented. At this juncture, one begins to wonder if the training of teachers in Cameroon is actually being given that importance that it deserves as in other countries such as the USA.

Training is defined as the systematic development in a person of the knowledge, attitudes and skills necessary for him to be able to perform adequately in a job or task whose demands can be reasonably well identified in advance and that requires a fairly standardised performance from whoever attempts it. (Edwards and Rowntree, 1981)

Specifically, teacher education is defined as, a very broad field of study and instruction concerned with professional preparation for careers in teaching, administration, or other specialities in education, particularly in the levels of preschool, elementary, and secondary education. Teachers in the Universities in Cameroon acquire teacher education principally through seminars and workshops. It is also called professional teacher education. Hence, in this context, education becomes the global concept in that the expression teacher education includes both the theoretical and practical components of a teacher preparation program. The term training is confined more to "well identified" instructional activities which require "fairly standardized performance."

The new teacher training programme has some well specified objectives drafted in line with the Competency Based Approach in Teaching. It is expected that, if it is well implemented by the teachers charged with its implementation, it will go a long way to contribute greatly towards Cameroon's emergence in 2035. The realization of this new school registered in the education Law of orientation and the necessity of a socioprofessional insertion requires an adoption of a pedagogic paradigm to draw up school syllabuses in line with the Competency-Based Approach using life skills. In this perspective, the New syllabuses for General Education, that of Teacher training and the referential for training for Technical Education, constitutes this great innovative movement of our educational system and in direct link with the orientations in the Growth and Employment Strategy Paper (GESP) that outlines from now till 2020, to provide minimum knowledge for all Cameroonian at the level of the first cycle of secondary education. These Syllabuses define, in terms of Knowledge, skills, attitudinal knowhow, essential competences that must be acquired by student teachers in the course of their training programme. This is a very good intension but if is not backed by appropriate actions, it will have very little positive outcome.

There are 60 Government Teacher Training Colleges in (GTTC) Cameroon. Of this number at least 10 are Government Bilingual Teacher Training colleges (GBTTC). There also exist 92 Private Teacher Training Colleges in Cameroon out of which 32 of them are found in Mfundi Division of the Centre Region. In the GTTC, 
teacher trainers are generally graduates from the Higher Teacher Training Colleges (HTTC) precisely from the Department of Sciences of Education. Today there are two types of Higher Teacher training Colleges in Cameroon. There is the HTTC that trains teachers for the secondary and high schools of general education on one hand. On the other hand is the HTTTC that trains teachers for the secondary and high schools of the technical and commercial colleges. As of now there are four Higher Teacher Training College in Cameroon. They are found in the following towns; Yaounde, Bambili, Maroua, and Bertoua. There are also four Higher Technical Teacher Training Colleges in Cameroon. They are found in Douala, Bambili, Kumba, and Ebolowa. HTTC Yaounde, HTTC Bambili and HTTC Maroua all have the Department of Sciences of Education as one of their Departments. An eligibility criterion for admissions into this Department is at least a first degree. This same eligibility criterion holds same for HTTC Maroua. However there exist a first cycle for this department in Maroua. Here the eligibility criteria is the possession of the GCE A' Level and the Teacher Grade one certificate. The graduates from this department are posted to teach any subject out of the 27 subjects that presently constitute the Grade one Teacher Training Programme in Cameroon. Some are also sent to teach any of the six professional subjects that exist at the GTTTC. It is important to state here that the contents they are expected to teach at the GTTC and GTTTC are not the same. It is worth noting that the HTTTC in Bambili equally operates a Department of Sciences of Education. Here teacher trainers are also trained and either posted to GTTC or GTTTC. Again there has been no blending of the content taught at the Departments of Sciences of Education at HTTC and HTTTC.

In the past this department was opened to degree holders in any discipline. This practice often met with much resistance as some people argued that there was need to narrow it down to candidates with academic backgrounds in Educational and social Sciences. Today most candidates who succeed at the entrance into the Department of Science of Education have first degree in Education followed by the Social Sciences. There is an aspect of the entry requirement that is being neglected. That is policy makers fail to understand that Education system is like a building. The foundation determines the nature of the building. Once the foundation is laid, every subsequent stage must be designed and developed taking into consideration the preceding stage(s). In this context, the content being taught at the Departments of Science of Education need to be in line with the content that is taught at the GTTC and GTTTC. This will enable them to train teacher trainers who will actually best prepare these teachers who lay the foundation of Cameroon's Educational System.

\subsection{Literature Review}

This section is made up of theoretical review, conceptual review and empirical review of literature. It is necessary to present some literature related to this paper.

\subsection{Theoretical Review}

This study had as a theoretical base, Taylor's Scientific Management Theory (1909). This theory in brief states that by optimizing and simplifying jobs, productivity would increase. It proposed the following four principles to guide the functioning of an organisation.

1. Replace working by "rule of thumb", or simply habit and common sense, and instead use the scientific method to study work and determine the most efficient way to perform specific tasks.

2. Rather than simply assign workers to just any job, match workers to their jobs based on capability and motivation, and train them to work at maximum efficiency.

3. Monitor worker performance, and provide instructions and supervision to ensure that they are using the most efficient ways of working.

4. Allocate the work between managers and workers so that the managers spend their time planning and training; allowing the workers to perform their tasks efficiently.

Linking this to this study optimizing and simplifying jobs will mean selecting candidates into the HTTC with academic backgrounds that will all take care of the content exigencies of the Grade one teacher training programme. This will create a friendlier atmosphere made of well trained teacher trainers who will guarantee a better performance on the part of the student teachers.

\subsection{Conceptual Review}

\subsubsection{Subject Allocation}

Within the context of this paper, subject allocation is the act of assigning a teacher trainer to teach a/some particular subject(s) from among the 27 subjects offered at the teacher training colleges in Cameroon. This is typically carried out in the college by the Dean of Studies when a new teacher trainer is received by the college. He consults the teacher to know his or her academic background, preferences, and then assigns subjects based on this knowledge and staffing needs.

\subsubsection{Teacher Training}

According to Dilshad (2010) the quality of teachers depends on the qualification of teachers and quality of pre- 
service and in-service teacher education they have acquired. This implies that the competence is based on how effective the teacher was trained in the training school. There is a significant body of literature that discusses the role that theory plays in educational theory and practice in teacher education. Darling-Hammond (2006: 8) noted that one of the perennial dilemmas of teacher education is how to integrate theoretically based knowledge that has traditionally been taught in university classrooms with the experience-based knowledge that has traditionally been located in the practice of teachers and the realities of classrooms and schools. Chen et al (2010: 91) revealed that the quality of teacher education programmes can be improved only if the teacher educators help student teachers to identify the gap between teaching and theory and continually facilitate them in connecting their learnt theory and practice. Stofflert and Stoddart (1994) argued that without the necessary theoretical knowledge it is a difficult challenge for teacher educators and researchers to change the training of teachers who teach in a traditional manner in order to change their educational practices. Korthagen et al (2006) constructed the following theoretical framework for student teacher learning and program change in teacher education:

1. Learning about teaching involves continuously conflicting and competing demands.

2. Learning about teaching requires a view of knowledge as a subject to be created rather than as a created subject.

3. Learning about teaching requires a shift from the curriculum to the learner.

4. Learning about teaching is enhanced through (student) teacher research.

5. Learning about teaching requires an emphasis on those learning to teach working closely with their peers.

6. Learning about teaching requires meaningful relationships between schools, universities and student teachers.

7. Learning about teaching is enhanced when the teaching and learning approaches advocated in the program are modelled by the teacher educators in their own practice.

Theory thus guides the research efforts of teacher educators and teachers in the sense that theoretical frameworks determine the problems that can be addressed by teacher educators, as well as, the adequacy of proposed solutions to these problems. In so doing, theory assists teacher educators and teachers to critically reflect on education policy issues that impact positively or negatively on best practice in the classroom. It is, therefore, important to recognise the role that theory can play in educational research and practice in teacher education. This means that teacher educators and teachers need to be aware of, and familiar with, the different theoretical frameworks that inform and shape educational theory and research in teacher education. Stated differently, it is necessary for teacher educators and teachers to recognise and be aware of the theoretical assumptions that influence the nature of educational theory and practice in teacher education in order to ascertain the impact of these assumptions on the theory and practice of teaching in the classroom. Such awareness will instil in teacher educators and teachers a critical astuteness that will be concerned with determining the most effective, relevant and best, practice in the classroom, and while at the same time ensuring that education practice is not directed by ideological and political concerns but rather by educational principles.

An educational institution performs a significant function of providing learning experiences to lead their students from the darkness of ignorance to the light of knowledge. The key personnel in the institutions who play an important role to bring about this transformation are teachers. As stated by National Council for Teacher Education (1998) in Quality Concerns in Secondary Teacher Education, the teacher is the most important element in any educational program. It is the teacher who is mainly responsible for implementation of the educational process at any stage. This shows that it is imperative to invest in the preparation of teachers, so that the future of a nation is secure. The importance of competent teachers to the nation's school system can in no way be overemphasized. The National Curriculum Framework 2005 places demands and expectations on the teacher, which need to be addressed by both initial and continuing teacher education.

\subsubsection{Conflict}

\section{Sources of Conflict}

The possible sources of conflict are poor communication, competition for common but scarce resources, incompatible goals and the like. Sonia and Damien, 2009 quoting Fisher (1997) notes that, "Both individuals and groups have undeniable needs for identity, dignity, security, equity, and participation in decisions that affect them". Frustration of these basic needs becomes a source of social conflict" According to Plunkett and Attner (1989), the sources of conflict include; shared resources, differences in goals, difference in perceptions and values, disagreements in the role requirements, nature of work activities, individual approaches, and the stage of organizational development. Gray and Stark (1984) suggested that there are six sources of conflict. These are:

1) Limited resources

2) Interdependent work activities

3) Differentiation of activities

4) Communication problems

5) Differences in perceptions

6) The environment of the organization.

According to these writers, conflict can also arise from a number of other sources, such as:1) Individual 
differences (some people enjoy conflict while others don't); 2) Unclear authority structures (people don't know how far their authority extends); 3) Differences in attitudes; 4) Task symmetries (one group is more powerful than another and the weaker group tries to change the situation; 5) Difference in time horizons (some departments have a long-run view and others have a short-run view). Another author Deutch in Campbell et-al $(1983: 187)$ identified a list of sources of conflict. These are; control over resources, preferences and nuisances, values, beliefs, and the nature of relationships between the parties. The classification of conflict is often made on the basis of the antecedent conditions that lead to conflict. Conflict may originate from a number of sources, such as tasks, values, goals, and so on. It has been found appropriate to classify conflict on the basis of these sources for proper understanding of its nature and implications. Following is a brief description of this classification.

Affective Conflict: This is defined as "a condition in which group members have interpersonal clashes characterized by anger, frustration, and other negative feelings"

Substantive Conflict: Jehn (1997) characterized this type of conflict as "disagreements among group members' ideas and opinions about the task being performed, such as disagreement regarding an organization's current strategic position or determining the correct data to include in a report".

Conflict of Interest: This is defined as an inconsistency between two parties in their preferences for the allocation of a scarce resource. This type of conflict occurs "when each party, sharing the same understanding of the situation, prefers a different and somewhat incompatible solution to a problem involving either a distribution of scarce resources between them or a decision to share the work of solving it"

Conflict of Values: This occurs when two social entities differ in their values or ideologies on certain issues. This is also called ideological conflict.

Goal Conflict: This occurs when a preferred outcome or an end-state of two social entities is inconsistent. In rare cases "it may involve divergent preferences over all of the decision outcomes, constituting a zero-sum game".

Realistic versus Non-realistic Conflict: Realistic conflict is associated with "mostly rational or goal-oriented" disagreement, non-realistic conflict "is an end in itself having little to do with group or organizational goals".

Institutionalized Conflict versus Non-institutionalized Conflict: Institutionalized conflict is one which is characterized by situations in which actors follow explicit rules. They display predictable behaviour, and their relationship has continuity. Most racial conflict is non-institutionalized where these three conditions are nonexistent.

Retributive Conflict: This conflict is characterized by a situation where the conflicting entities or factions feel the need for a drawn-out conflict to punish the opponent. In other words, each party determines its gains, in part, by incurring costs to the other party.

Misattributed Conflict: This relates to the incorrect assignment of causes (behaviors, parties, or issues) to conflict.

Displaced Conflict: This type of conflict occurs when the conflicting parties either direct their frustrations or hostilities to social entities that are not involved in conflict or argue over secondary, not major, issues.

Conflict Resolution Skills

Strategies David and Johnson (1996) hold that Conflict resolution and peer mediation programs are often promoted as a way to reduce violence in schools. Management of conflict is a human relations concept long recognized in business and industry as a necessary component of the developmental process. Sweeney and Caruthers (1996) define conflict resolution in a most general and concise way, "the process used by parties in conflict to reach a settlement".

Hocker and Wilmot (1985) initially discuss conflict management styles in terms of assumptions. Their assumptions are:

\section{The First Distinction: Process versus Structural Analyses}

Process and structural analyses appear to be fundamentally different methods of perceiving and understanding phenomena. Thomas, 1976 synthesis of dyadic conflict theory underscored the distinction, assembling much of that literature into two separate process and structural models of conflict behaviour. Process models of behaviour place the parties in a temporal sequence of events. Behaviour is assumed to be directly influenced by preceding events and anticipation of subsequent events. Structural models focus upon conditions, relationships between those conditions, and their influence upon behaviour. At a given moment, those conditions are viewed as exerting forces upon behaviour. Whereas a process model places parties in a sequence of events, a structural model places them in a web of forces. A series of verbal threats, acts of physical aggression, and an exchange of evaluative remarks are events. When these events, or a party's anticipation of them, are seen as influencing that party's behaviour, the behaviour is being explained in process terms. Conflict of interest, norms, beliefs, attitudes, and skills are conditions. That is things which exist over a period of time. As such, they are structural constructs for explaining behaviour. 


\section{The Second Distinction: internal versus External Sources of Influence}

This distinction refers to two different loci for the origins of behaviour. "Internal" models emphasize events and conditions within a party which influence behaviour. Parties are seen as decision-making entities confronted with alternatives and choice points. Variation in behaviour is assumed to be an outcome of differences in the processes and structures of this decision making. By contrast, "external" models focus upon events and conditions outside the party which shape behaviour. As Bugental, 1978 noted that, the implicit assumption is that parties are fairly interchangeable in their reactions to processes and conditions in their environment. He noted that these processes and conditions are sufficient to explain behaviour.

\section{The Four Perspectives of conflict}

These two distinctions combine logically to identify four perspectives upon conflicts: "external process", "external structural", "internal process", and "internal structural". Although this scheme was developed independently, it bears a strong resemblance to the scheme used by Clark and Krone, 1972 to classify their organization development interventions. Subsequent discussion of each perspective will focus on diagnosis and on intervention strategies. But the four perspectives also help to explain the divergence in definitions of "conflict" in the literature: as behavioural interference, threats, or competition (external process); as conflict of interest or objective role conflict (external structure); as experienced frustration or the intent to injure or to interfere with an opponent (internal process); or as personal incompatibilities and antagonistic attitudes or predispositions (internal structure).

\section{The External Process Perspective}

This perspective emphasizes the causal effects of events which impinge upon a party from outside. A party's behaviour is seen as a reaction to the behaviour of other parties, in "stimulus-response" fashion, and this behaviour in turn evokes a behavioural response from them.

\section{Diagnosis}

Sources of conflicting behaviour are sought in other stimulus behaviours. Conflict behaviour has been asserted to be a response to competition, threat, negative evaluation, encroachment, and coercion. Third party interventions also may be viewed as external events to which the parties react, as in process interventions discussed by Schein and Walton.

\section{Intervention: "interaction Management"}

Since the manner of interaction is seen as the basis of the conflict, the change agent's focus is on changing interactions. This change objective is non-substantive in that the change agent is not especially concerned with the content of the interactions (i.e., the issues of the conflict situation), but with specific behaviours used by the parties in negotiating or otherwise attempting to influence each other. The class of interventions by which change agents attempt to achieve this objective is termed "interaction management".

Change agents may intervene directly into the interaction to control behaviour by acting as "referee" to stop unfair behaviour, rephrasing statements to make them less provocative, acting as timekeeper and gatekeeper to insure equal time, and so on. They may also act as role models to provide an example of effective modes of interaction. For example, a change agent may purposely be non-evaluative and descriptive. The crucial nature of the intervention in this case is the change agent's type of behaviour. The parties may adopt similar behaviour through identification with the change agent, thereby reducing defensiveness and facilitating problem solving.

\section{The External Structural Perspective}

The external structural perspective places the causes of behaviour in conditions outside the parties. Conditions in the environment are seen as motivating, constraining, or channelling behaviour.

Diagnosis

In a review of the literature on organizational conflict, (Thomas, 1976) identified three clusters of external conditions which influence conflict behaviour. They are conflict incentives, social pressures, and rules and procedures. A conflict incentive is used in a broad sense to include the objectives of the parties and the manner in which satisfaction of those objectives is linked. Two central components discussed have been the stakes involved, and the conflict of interest between goals of the conflict parties. Social pressures can be viewed as barriers and forces. He differentiated between pressures from constituents and ambient social pressure. Finally, the conflict parties can be viewed as interacting within a framework of rules and procedures which shape their negotiations as well as their opportunities to interfere with each other. The conflict behaviour of the two parties has been linked to several aspects of established negotiating procedures frequency of contact, barriers to openness, formality, and sequencing of issues. Explicit decision rules evolve to cover sensitive issues. Various forms of mediation or arbitration mechanisms may be available when the parties deadlock.

Intervention: "Contextual Modification"

Change objectives focus upon alteration of external conditions which exert forces upon the parties. Interventions which seek to alter this external context of the parties' behaviour are labelled "contextual modification". Methods to change the responsibilities of either party, formal and informal rules, job descriptions, incentives, budgets, control mechanisms, social pressures, etc., fit this category. These methods might include: (a) formally dictating 
a change in policy or goals of either or both parties, (b) mandating a negotiation session between parties in which they have to compromise their budget demands, (c) changing the composition of members belonging to either or both parties, (d) changing the social pressures which other bystanders exert upon the parties, and (e) instituting super ordinate goals so that the parties benefit by cooperating with each other. Aspects of contextual modification are now receiving increasing emphasis as the field of organizational behaviour leans more heavily toward organizational design.

\section{The Internal Process Perspective}

This perspective seeks the source of behaviour in the sequence of events which occurs within a party. In the case of individuals, behaviour is seen as an outcome of the logic or "psycho logic" of perceptions, ideas, and emotions. Whereas the internal structural perspective emphasizes consistencies and personal fixities, this perspective emphasizes the moment-to-moment changes in the individual's phenomenology and the choices which are made at any given moment. The individual is an ongoing process, rather than an object with stable characteristics, a view emphasized in humanistic psychology. When the conflict party is a larger social unit (a work group or organization), this focus expands to include the ongoing interpersonal decision processes within the unit which shape its behaviour toward other units.

\section{Diagnosis}

Diagnostic efforts centre upon understanding the sequence of internal events which are shaping the conflict episode. In his process model, Thomas, 1976 emphasized the importance of understanding the specific nature of the actual or anticipated frustrations which begin conflict episodes. That is the underlying concerns or agendas of the parties. That model also emphasized the importance of the parties' conceptualizations of the conflict situation. That is their definitions of the issues and their assumptions about possible outcomes. The change agent operating from this perspective will want to understand the strategic and tactical logic of each party. Parties may adopt political strategies involving coalitions, interpersonal strategies involving games or ploys, bargaining strategies involving power and so on. Occasionally violence may be understood as a deliberate and rational tactic under this perspective, although the parties may also realize the advantages of limiting or managing their conflict. Less rational decision processes also are important from this perspective. Conflict behaviour may stem from misperceptions, projection, selective attention and recall, polarization and stereotyping, and the inability to recognize alternatives.

\section{Intervention: "Consciousness Raising"}

Given the assumption that the parties' conflict behaviour stems from their internal processing of decisions, the change agent's objective is to influence the parties' perceptions, cognitions, and emotions regarding the ongoing conflict. Such interventions are termed "consciousness raising" interventions. Included are many traditional interventions used by the trainer of a sensitivity training group, where discussions of "here and now" experiences can lead to new appreciation of an ongoing interpersonal process, awareness of alternative behaviours and their effects, correction of perceptual distortions, and working-through of feelings. Also included are individual or joint counselling sessions aimed at helping the parties to recognize their frustrations and objectives, think through the consequences of alternative paths, and work through ambivalences about a course of action. Although internal process or consciousness raising interventions may result indirectly in altered modes of interaction between parties, decisions regarding external structural change, or long-run changes in a party's internal structuring, these are not the primary objectives of an internal process intervention. The primary objective is to improve the parties' internal processing of decisions regarding the current conflict episode. Although the term "consciousness raising" carries connotations of neutral activities intended only to bring some phenomenon into awareness, these interventions may also involve advocacy and persuasion. Nevertheless, consciousness-raising interventions tend to be the most humanistic, in the sense of treating the parties as responsible decision makers.

\section{The Internal Structural Perspective}

This perspective seeks the causes of the parties' behaviour in relatively stable characteristics within them, and in the manner in which these characteristics are organized. The parties' behaviour is viewed as an expression of their make-up. This "personality" or "organization" is seen as a compelling influence upon behaviour, predisposing parties to characteristic patterns of behaviour.

\section{Diagnosis}

An explanation of the general status of a party's relationships with other parties is sought in terms of the party's characteristics, whether based upon instinct, culture and socialization, or other factors. To some extent, a party's conflict-handling behaviour may be seen in terms of habitual response hierarchies and styles. Although trait theories are not currently in vogue, some research evidence indicates a degree of regularity in conflict-related behaviours. For example, Gormly and Edelberg, 1974 found evidence that an individual's assertiveness is reliable across situations. The party's general behaviour also may be understood in terms of stable underlying attributes which shape behaviour: motives and needs, value systems, information-processing limitations, characteristic defense mechanisms, and diagnostic and problem-solving skills. In diagnosing conflict in a 
specific relationship, attention may be focused upon incompatibilities between styles, needs, etc., of the two parties.

\section{Intervention: "Selection and Training"}

As in the internal process perspective, the change agent is concerned with altering things which are internal to the parties. But while the internal process perspective sought to influence decision-related events within the parties during a specific conflict episode, the internal structural perspective is concerned directly with changing the parties themselves. That is with making stable changes which will continue to influence the parties' behaviour across a number of episodes. The emphasis is upon lasting change rather than facilitating a single here-and-now interaction. Change efforts are therefore likely to be more systematic, involving a program of interventions. One approach to changing the conflict-handling characteristics of individuals in a given organizational position is through the selection of those people. Similar screening procedures may be applied to organizations themselves. "Training" is used here to denote all interventions directed at producing lasting changes in parties which have already been selected. This may also mean modifying training content to mitigate aspects that were initially sources of conflict.

\section{Implications}

This meta-model or framework can be used to help potential change agents (School Heads) identify their diagnostic and intervention styles. This will be done by surfacing assumptions about the source of conflict, and by classifying their preferred interventions. Development of specialized styles may be functional for a change agent, and the four perspectives help to identify the change agent's strengths. By implication they also help to identify blind spots. One normative suggestion deriving from this article is that the change agent and practitioner should be explicit about their conceptualizations, and explicitly consider the four kinds of diagnoses and intervention strategies in choosing how to deal with an important conflict situation. In effect, these four perspectives can be used as a "checklist" to suggest the full range of possibilities. Having a wider choice of alternatives would enable a more realistic cost/benefit analysis. That is an assessment of the costs of each type of diagnosis and corresponding intervention strategy versus the expected short or long range benefits to be derived from the interventions. Even if change agents themselves are not equally skilled in implementing the four perspectives, conscious awareness of all four approaches can allow them to involve appropriate others and prevent them from using their strengths inappropriately. If no single person can be expert in applying more than one or two perspectives, a team can be composed so that all four perspectives will be equally considered, coordinated, and applied as necessary. The present meta-model of the four perspectives may give the team a common framework for organizing and appreciating their diversity of approaches, resulting in a true systems approach to conflict management. Such an approach may become more necessary as the school as an organization faces more complex, dynamic, and changing contexts, where the sources of frequent conflicts are complex and multidimensional. Although the four perspectives and model emerged from a review of conflict literature, they are easily generalizable to the understanding and influencing of other behavioural phenomena. If management is viewed as a process of influencing others, the four perspectives can be used to classify approaches to management in general:

(a) The external process approach is roughly equivalent to close supervision and direct control of others' work.

(b) The internal process approach includes counselling and helping individuals to define their own goals, which are basic elements of Management by Objectives.

(c) The external structural approach involves management through incentives, rules, control systems, and organizational design technologies.

(d) The internal structural approach includes recruiting, placement, and training. In short, this meta-model provides a new approach to classifying managerial style. It emphasizes the individual's implicit philosophy of how people are influenced. Rather than inter-personal manner (whether one is considerate, assertive, etc.). This scheme combines a number of important philosophies of management not only the classic Behavioural Science process distinctions of close Theory X supervision versus. Theory Y counselling and goal setting, but also the Management Theory emphasis on incentives and control systems, and Industrial Psychology emphasis on selection and training.

\subsection{Empirical Review}

In Bermuda, a study was conducted by Cross field and Bourne (2018) entitled, "Management of interpersonal conflict between Principals and Teachers in Selected Secondary schools in Bermuda". The study used quantitative approach to identify and manage factors contributing to interpersonal conflicts between principals and teachers in selected Secondary Schools in Bermuda. The findings of the study revealed that despite the fact that the physical environment of the schools appeared healthy, there were interpersonal and intergroup sources of conflict. The study identified the following factors which led to conflicts in schools; limited resources, communication problems, differences in perceptions and imposition of strict deadlines for various activities. A study was conducted in Romanian schools by Catana (2015) entitled, "Conflicts between Teachers: Causes and 
Effects". Catana "e study was based on a field research covering both urban and rural areas. The study used a mixed research methodology and descriptive survey design in place. Data was collected through a questionnairebased inquiry and focus-groups for teachers and school managers. The main causes for professional conflicts between teachers were identified as: different information and previous experience related to a certain issue; different perception for the same problem; different motivation, interests and personal objectives; and inequitable allocation of task. Catana (2015) in her study, she indicated that difference perceptions were related to a particular individual.

In most Romanian schools, teachers received different motivations and held different interests or personal objectives on the same issue and different knowledge concerning a subject. This meant that different personal experiences between teachers were sources of conflict and led to disunity and mistrust within schools. Besides, as communication depends on the effectiveness of the school management, the findings of the study showed that lack of proper communication between teachers resulted in misinformation and inefficiency in lesson delivery to learners in most Romanian schools. This meant that when there was a communication breakdown, conflicts arose and learners were equally affected.

In Kenya, a study was conducted by Jared and Thinguri (2017) entitled, "A critical analysis of the impact of head teachers and deputy head teachers' conflict development on team work in public primary schools in Kenya". The study sought to establish the root cause of conflicts among the head teachers and deputy head teachers in public primary schools in Kenya. The researchers used content reviews and desk analysis function design. Jared and Thinguri (2017) revealed that in service, there were long serving teachers who have gathered accumulative several years of experience and the newly employed teachers with latest and higher qualifications. Findings were that when long serving teachers held offices of head in schools while given a young deputy head teacher, conflicts were there on experience and qualifications. The study indicated that young teachers perceived the elderly head teachers as old fashioned without modern leadership skills. In the similar case, Shahmoharumadi (2014) held that the old head teachers despised the young deputies as inexperienced who could not command respect and have little knowledge in the teaching profession.

In the same vein, Kipyego (2013) stated that those teachers only taught to earn a living in their profession and they ever complained, murmured, grumbled and even fought those who made them to have work done. Jared and Thinguri (2017) further indicated in their study that in Kenya, due to lack of jobs, people joined teaching profession simply because they did not have other choices. As a result, conflicts erupted in schools on the basis of unethical behaviour, making head teachers to have very tough time to correct their teachers and in some cases deputies from time to time. In the similar case, Madziyire et al (2010) argued that in some schools, the management might have had interest to save the money in their bank accounts in order to generate interest while at the same time demanding for excellent performance from the teaching staff in school. Favouritism is a situation of preferring someone or a group of people from a segment of teachers in an educational organisation simply because administration likes them. Jared and Thinguri (2017).

In some schools, head teachers had their favourite teachers. This made conflict to arise in schools due to privileges some teachers received from the school administration on the basis of favouritism. In a similar stance, a study conducted in Kenya by Omboko (2010), revealed that head teachers at times favoured certain teachers where the children to such teachers do not even pay school fees. This created conflict within the school, which remained unresolved over a long period of time and resulted into anxiety and stress on those teachers who were sidelined. Omboko in Kipyego (2013), stated that head teachers usually favoured other tutors at the expense of others, which led to discontentment among other teachers in school. Further, Kipyego (2013), stated that by not treating workers equally, leaders encouraged a sense of resentment and disunity that could demotivate workers and damage togetherness and team spirit.

In South Africa, a study was conducted by Plessis and Cain (2017) entitle, "Exploring perceived sources of conflict among educators in three Eastern Cape schools". This study used qualitative interpretive case study to explore the causes of conflict among teachers in three primary schools residing in previously disadvantaged social contexts. The two researchers in their study revealed that tensions have the potential to result in dysfunctional conflict that negatively impact on the teachers, learners and learning within the school. In their study, they found out that perceived conflicts in school include: limited possibilities for promotion, limited resources, need for power, favouritism, lack of respect and tolerance for different opinions, different beliefs and viewpoints as a result of different contexts, lack of communication, management and leadership issues as well as roles and responsibilities: lack of consultation and uncertainty, strategies, unfair class allocations, teachers having higher qualifications than their head teachers and responsibilities not being shared equally. Under ethical misconduct, included constant absenteeism from work, favouritism of some teachers by the head teachers, incompetence of some head teachers, lack of preparedness by some teachers, not submitting teaching files, constant late reporting for work by both teachers and head teachers, negative work culture by teachers, female teachers dressing inappropriately, offering school places to undeserving pupils and use of vulgar language by head teachers. This can also be looked at as a form of civic awareness on the part of the participants that 
provided such information.

Danial et al, 2011 conducted a similar study to assess the effectiveness of the teacher training programmes offered by Kohat University of Science \& Technology Kohat (Khyber Pukhtunkhwa) Pakistan. After analysis of data, the researchers arrived at results that B.Ed programme is effective one and it meets the needs and requirements of the prospective teachers but it has some week points i.e. it does not inculcate Islamic ideology, distribution between theory and practice is not appropriate, it does not provide sufficient base for research and introduce modern instructional strategies.

\subsection{Statement of the Problem}

The quality of education is dependent on the availability, quality and efficiency of teachers and administrators. In the same respect, a very sound and important relationship between teachers and the school administration is ideal, if good performance is to be attained. The result of the Grade one Teacher Training Examination in the past recent years have been qualitative very poor. Most of the student teachers pass with the grades Average and Averagely Good. There had not been a student with the grades Very Good or Excellent. There is a general assumption that every graduate of the Department of Science of Education at HTTC can teach every subject of at the GTTC. This assumption has been highly doubted as there have been several reports of teacher trainers resisting or turning down some subjects allocated to them by the Deans of study at the GTTCs. This have often generated intrapersonal and interpersonal conflicts. Intrapersonal conflict is conflict with self while interpersonal conflict is conflict with one another. A teacher who is not well trained and feels unequipped to teach a particular subject is experiencing intrapersonal conflict. He or she cannot produce student teachers with quality results. When a teacher trainer turns down a subject allocated to he or she, this leads to an interpersonal conflict between $\mathrm{s}(\mathrm{he})$ with the Dean of study. It was not clear if conflicts existed between teacher trainers and Deans of study at the GTTCs. If conflicts did exist, it was not clear of types of conflict and how they were mitigated. What is certain is that once two or more persons relate with each other, there are bound to be conflicts. This holds even true for lovers such as husband and wife. Every conflict needs to be resolved amicably. When conflicts linger on or are poorly resolved, the aftermath can be disastrous. This study therefore, explored conflicts between teacher trainers and the Deans of study caused by subject allocation at some selected GTTCs in Cameroon.

\subsection{Purpose of the Study}

The purpose of the study was to find out the effectiveness of the model of subject allocation to teacher trainers at the GTTC in Cameroon.

The model is a one to many mapping. It states that any teacher trained at the Department of Science of Education at HTTC Bambili can teach any of the 27 subjects offered at the GTTC in Cameroon. So this study in essence was designed to investigate whether this model of one to many allocation of subjects to teacher trainers at the GTTC in Cameroon is effective.

\subsection{Research Questions}

Three research questions guided the study:

1. Can every teacher trainer effectively teach all subjects of the teacher training programme?

2. To what extent does subject allocation to teacher trainers generate conflicts within the school?

3. How should conflicts generated by subject allocation to teacher trainers be resolved?

\subsection{Methodology}

The study incorporated descriptive survey that sought to ascertain the effectiveness of the allocation of subjects to teacher trainers at the GTTCs in Cameroon. Participants, who were randomly selected, consisted of 40 teacher trainers who are graduates of the Department of Science of Education at the HTTCs and 4 Deans of studies at the GTTCs. The teacher trainers were randomly selected from GBTTC Bamenda and GBTTC Bafoussam. They had a population of 70 and 46 teacher trainers respectively. A closed- ended questionnaire made up of 27 items from the Grade one Teacher Training Programme was served as indicators of subject allocation to the teacher trainers. They were asked to state YES or NO to each item which asserted that they could effectively teach the subject in question. Here a percentage of 75(mean of 1.25) and above was considered positive. It should be noted here that an ideal positive situation would have had $100 \%$ for each statement. A second set of closed-ended questionnaire composed of 10 items was administered to 4 Deans of study of the GTTCs. They were equally expected to state either YES or NO to each statement. A review of literature on origins of conflict due to subject allocation and models of conflict resolution within an organisation served as indicators of conflicts and perspectives respectively. The questionnaires were validated by 10 teacher trainers and 2 Deans of study respectively who did not take part in the study. Data were analyzed descriptively, using percentages and means. The implication of the percentages in each sections of the questionnaire was explained. Items were grouped according to research questions and the mean of all the percentages of the items per research question (global mean) was used to 
answer and discuss the research questions.

\subsection{Findings and Discussions}

Research Question one: Can every teacher trainer effectively teach all subjects of the teacher training programme? Table 1: Descriptive analysis of the extent to which every teacher trainer can effectively teach all the subjects of the Grade one Teacher Training Programme

\begin{tabular}{|c|c|c|c|c|c|}
\hline SUBJECTS & $\mathrm{N}$ & Minimum & Maximum & Mean & $\begin{array}{l}\text { Standard } \\
\text { Deviation }\end{array}$ \\
\hline Didactics of Citizenship & 40 & 1.00 & 2.00 & 1.1000 & 0.30382 \\
\hline Pedagogic Supervision & 40 & 1.00 & 2.00 & 1.1250 & 0.33493 \\
\hline General pedagogy & 40 & 1.00 & 2.00 & 1.1500 & 0.36162 \\
\hline Sociology of Education & 40 & 1.00 & 2.00 & 1.1750 & 0.38481 \\
\hline Educational Psychology & 40 & 1.00 & 2.00 & 1.2000 & 0.40510 \\
\hline Philosophy of Education & 40 & 1.00 & 2.00 & 1.2250 & 0.42290 \\
\hline Deontology and Professional Ethics & 40 & 1.00 & 2.00 & 1.2500 & 0.43853 \\
\hline Didactics of Practical Activities & 40 & 1.00 & 2.00 & 1.2500 & 0.43853 \\
\hline Didactics of Nursery Activities & 40 & 1.00 & 2.00 & 1.2750 & 0.45220 \\
\hline School Administration and Legislation & 40 & 1.00 & 2.00 & 1.3000 & 0.46410 \\
\hline $\begin{array}{l}\text { Educational Policies and Comparative } \\
\text { Education }\end{array}$ & 40 & 1.00 & 2.00 & 1.3500 & 0.48305 \\
\hline Introduction to Action Research & 40 & 1.00 & 2.00 & 1.4000 & 0.49614 \\
\hline Didactics of History and Geography & 40 & 1.00 & 2.00 & 1.4500 & 0.50383 \\
\hline Agriculture & 40 & 1.00 & 2.00 & 1.4750 & 0.50574 \\
\hline $\begin{array}{l}\text { Didactics of Sciences and Environmental } \\
\text { Education }\end{array}$ & 40 & 1.00 & 2.00 & 1.6000 & 0.49614 \\
\hline English Didactics & 40 & 1.00 & 2.00 & 1.6750 & 0.47434 \\
\hline English (First Language) & 40 & 1.00 & 2.00 & 1.7500 & 0.43853 \\
\hline Didactics of Mathematics & 40 & 1.00 & 2.00 & 1.7750 & 0.42290 \\
\hline $\begin{array}{lll}\text { Information } & \text { and } & \text { Communication } \\
\text { Technologies } & & \\
\end{array}$ & 40 & 1.00 & 2.00 & 1.7750 & 0.42290 \\
\hline Introduction to Educational Statistics & 40 & 1.00 & 2.00 & 1.8000 & 0.40510 \\
\hline Didactics of Educational Technology & 40 & 1.00 & 2.00 & 1.8250 & 0.38481 \\
\hline Didactics of Songs and Music & 40 & 1.00 & 2.00 & 1.8500 & 0.36162 \\
\hline French (Second Language) & 40 & 1.00 & 2.00 & 1.9250 & 0.26675 \\
\hline French Didactics & 40 & 1.00 & 2.00 & 1.9500 & 0.22072 \\
\hline Sports and Physical Education & 40 & 1.00 & 2.00 & 1.9500 & 0.22072 \\
\hline Didactics of Sports & 40 & 1.00 & 2.00 & 1.9750 & 0.15811 \\
\hline $\begin{array}{l}\text { Didactics of National Languages and } \\
\text { Cultures }\end{array}$ & 40 & 1.00 & 2.00 & 1.9750 & 0.15811 \\
\hline Averages & 40 & 1.00 & 2.00 & 1.5344 & 0.38615 \\
\hline
\end{tabular}

Table 1 above revealed that the teacher trainers could effectively teach $29.6 \%$ of the 27 subjects of the teacher training programme. None of them indicated that they can effectively teach all the subjects of the Grade one Teacher Training Programme. For a subject to be considered to be well within the competence of the teacher trainers, at least 30 out of 40 should indicate that they can effectively teach the subject. A subject with a mean of 1.25 corresponds to 30 out of 40 teacher trainers being able to effectively teach that subject. A subject with mean more than 1.25 corresponds to less than 30 out of 40 teacher trainers being able to effectively teach that subject. It was observed that only 8 subjects out of the 27 subjects were well within the sphere of academic competence of the 40 teacher trainers sampled. That 8 is $29.6 \%$ of 27. That is Didactics of Citizenship, Pedagogic Supervision, General Pedagogy, Sociology of Education, Educational Psychology, Philosophy of Education, Deontology and Professional Ethics, and Didactics of Practical Activities. They had a mean of 1.25 and less. The rest of the subjects had means above 1.25. The implication of this is that, out of the 40 teacher trainers sampled 30 and above indicated that they could effectively teach just 8 out of the 27 subjects. By extrapolation this means that the majority of the 27 subjects $(70.4 \%)$ could be effectively taught by less than the cut point number (30). The higher the mean, the less the number of teacher trainers who indicated that they could teach the subject in question. Subjects such as English (First Language, Didactics of Mathematics, Information and Communication Technologies, Introduction to Educational Statistics, Didactics of Educational Technology, Didactics of Songs and Music, French (Second Language), French Didactics, Didactics of Sports, Didactics of National Languages and Cultures had very high means. These are the subjects which recorded the least number of teacher trainers 
who could effectively teach them. As a matter of fact, out of the 40 teacher trainers sampled, the number of teacher trainers who indicated that they could effectively teach these subjects ranged from 0 to 3 . A mean of 1.5 corresponds to 20 out of 40 teacher trainers being able to effective teach a subject. The average mean was calculated to be 1.5344.This mean is above 1.25 (the acceptable mean) meaning that on a general note, less than twenty out of the forty teacher trainers accepted that they could effectively teach all of the 27 subjects of the teacher training programme.

Research Question two: To what extent does subject allocation to teacher trainers generate conflicts within the school?

Table 2: Descriptive analysis of the extent to which subject allocation to teacher trainers generate conflicts within the school

\begin{tabular}{|l|c|r|r|r|c|}
\hline \multicolumn{1}{|c|}{ Conflict Indicators } & $\mathrm{N}$ & Minimum & Maximum & Mean & $\begin{array}{l}\text { Standard } \\
\text { Deviation }\end{array}$ \\
\hline $\begin{array}{l}\text { Teachers sometimes resist subjects allocated } \\
\text { to them }\end{array}$ & 4 & 1.00 & 2.00 & 1.0000 & 0.00000 \\
\hline $\begin{array}{l}\text { Almost every academic year I have problems } \\
\text { with teachers as a result of subject allocation }\end{array}$ & 4 & 1.00 & 2.00 & 1.0000 & 0.00000 \\
\hline $\begin{array}{l}\text { Teachers sometimes turn down subjects } \\
\text { allocated to them }\end{array}$ & 4 & 1.00 & 2.00 & 1.5000 & 0.57735 \\
\hline $\begin{array}{l}\text { Teachers have reported me to hierarchy for } \\
\text { assigning them to teach some particular } \\
\text { subjects }\end{array}$ & 4 & 1.00 & 2.00 & 1.7500 & 0.50000 \\
\hline $\begin{array}{l}\text { Some teachers have thrown insults at me as a } \\
\text { result of subject allocation }\end{array}$ & 4 & 1.00 & 2.00 & 1.7500 & 0.50000 \\
\hline Averages & 4 & 1.00 & 2.00 & 1.4000 & 0.31547 \\
\hline
\end{tabular}

Table 2 above shows some interesting revelations. A mean of 1.0 corresponds to an instance where all the four Deans of Study accepted a statement. A mean of 1.5 corresponds to the instance where two out of the four Deans of Study accepted a statement. Finally a mean of 1.75 corresponds to an instance where one out of the four Deans of Study accepted a statement. This reveals that all the four Deans of Study accepted that teachers sometimes resist subjects allocated to them and that almost every academic year they have problems with teachers as a result of subject allocation. Two out of the four Deans of Study accepted that teachers sometimes turn down subjects allocated to them. Finally one out of the four Deans of study accepted that teachers have reported him to hierarchy for assigning them to teach some particular subjects and that some teachers have thrown insults at him as a result of subject allocation. Hence three out of five items had undesirable means. (Low means which indicated high acceptance rate). This brings us to the summary that $60 \%$ of the respondents accepted that subject allocation to teacher trainers generate conflicts within the school. This is indicated by items with means less than 1.75. The mean of 1.75 and above were considered not to be alarming. The average mean is calculated to be 1.40 . So the rate at which conflicts are generated at the teacher training colleges as a result of subject allocation is alarming.

Research Question three: Can conflicts generated by subject allocation to teacher trainers be locally resolved?

Table 3: Descriptive analysis of the extent to which conflicts generated by subject allocation to teacher trainers can be locally resolved

\begin{tabular}{|l|c|r|r|r|r|}
\hline Conflict Resolution & $\mathrm{N}$ & Minimum & Maximum & Mean & $\begin{array}{c}\text { Standard } \\
\text { Deviation }\end{array}$ \\
\hline Sometimes I have to impose & 4 & 1.00 & 1.00 & 1.0000 & 0.00000 \\
\hline $\begin{array}{l}\text { Sometimes I allow teachers to concert with } \\
\text { other colleagues and swap subjects }\end{array}$ & 4 & 1.00 & 1.00 & 1.0000 & 0.00000 \\
\hline Sometimes I pair teachers to do team teaching & 4 & 1.00 & 1.00 & 1.0000 & 0.00000 \\
\hline $\begin{array}{l}\text { Sometimes I completely replace the subject } \\
\text { with the teachers' preferences }\end{array}$ & 4 & 1.00 & 1.00 & 1.0000 & 0.00000 \\
\hline $\begin{array}{l}\text { Sometimes we have hired experts to train our } \\
\text { teachers in some areas requiring expert } \\
\text { knowledge }\end{array}$ & 4 & 1.00 & 2.00 & 1.7500 & 0.50000 \\
\hline Total & 4 & 1.00 & 2.00 & 1,14 & \\
\hline
\end{tabular}

Table 3 above portrays that generally $85 \%$ of the respondents acknowledged that conflicts generated by subject allocation to teacher trainers can be locally resolved. That is it portrayed by items with mean less than 1.75. The high mean is an indication of rareness in their usage. Most frequently used solutions had means less than 1.75 . A mean of 1.0 indicates $100 \%$ subscription to a conflict resolution strategy. Looking at the table it is 
observed that, all the Deans of Study accepted that sometimes they have to impose subjects on teacher trainers. Sometimes they allow teacher trainers to concert with other colleagues and swap subjects. Sometimes they pair teacher trainers to do team teaching. Finally sometimes they completely replace the subject with the teachers' preferences. Only one out of the four Deans of Study indicated that sometimes they hired experts to train their teachers in some areas requiring expert knowledge. It is seen that only one item out of the five items recorded an alarming mean. The rest of the items were largely made use of.

\subsection{Implications of the Findings}

Table 1 reveals that the teacher trainers indicated that they could effectively teach $29.6 \%$ of the 27 subjects of the grade one teacher training programme. The ideal situation here would have been that $100 \%$ of the respondents accepted that they could teach any subject of the grade one teacher training programme. The reality is that less than 20 of the respondents accepted that they could teach any subject of the teacher training programme. This therefore shows that the belief that every graduate from the Department of Science of Education can teach any subject of the grade teacher training programme remains an illusion. It is an assumption which has been proven by this paper to be untrue. This means in reality that none of these graduates chosen at random can effectively teach every subject of the grade teacher training programme. Another implication is that, the probability that a teacher trainer chosen at random will effectively teach any subject chosen at random is $8 / 27$ (0.3). This low probability is the reason behind the frequent conflicts observed at the teacher training colleges due to subject allocation to teacher trainers.

Majority of the teachers interviewed indicated that they could effectively teach General Pedagogy, Educational Psychology, Pedagogic Supervision, Philosophy of Education, Sociology of Education, Didactics of Citizenship Education, Deontology and Professional Morals and Didactics of Practical Activities. On the other hand, a minority of the teacher trainers accepted they could effectively teach Educational Statistics, First Language (English), Second Language (French), Didactics of Songs and Music, Didactics of Sciences and Environmental Education, Didactics of Sports and Physical Education, French Didactics, Didactics of Mathematics, English Didactics, Didactics of National Languages and Cultures, Information and Communication Technologies, Agriculture, and Sports and Physical Education. This clearly shows the effects of the teacher trainers' academic background on the choice of subject to be taught at the GTTC. Most of the teacher trainers did either Education or Social Sciences at the first degree level. This explains why a majority of them accepted they could effectively teach most of the core professional subjects. These are areas they probably majored in at the first degree level. They cannot effectively teach the second group of subjects because they probably have a weak academic background in them.

Table 2 shows that $60 \%$ of the respondents accepted that subject allocation to teacher trainers generate conflicts within the school. This means that the probability that a graduate from the Department of Science of Education posted to GTTC will happily and effectively teach any subject allocated to he/she is $3 / 10(0.3)$. On the other hand this means that the probability that a graduate from the Department of Science of Education posted to GTTC will not happily and effectively teach any subject allocated to he/she is $6 / 10(0.6)$. While $30 \%$ are likely to be happily teaching subjects allocated to them, $60 \%$ will likely reject or be grudgingly teaching subjects allocated to them. With this kind of conflicting situation (internal and external), the output of the teachers in question cannot be optimal. This implies that a majority of the teacher trainers largely fall short of the demands of the grade one teacher training programme in Cameroon. This is probably because the selection of candidates into the Department of Science of Education at the HTTCs and their subsequent training are not tailored to meet the demands of the subjects at the GTTCs. They seem to be done in isolation or neglecting the realities of what they are expected of upon graduation.

In a related study Cross field and Bourne (2018) revealed that despite the fact that the physical environment of the schools appeared healthy, there were interpersonal and intergroup sources of conflict. The study identified the following factors which led to conflicts in schools; limited resources, communication problems, differences in perceptions and imposition of strict deadlines for various activities. Also in another study by Catana (2015), she identified main causes for professional conflicts between teachers as: different information and previous experience related to a certain issue; different perception for the same problem; different motivation, interests and personal objectives; and inequitable allocation of task. She indicated that differences in perceptions among individuals could lead to conflicts. At the individual level, the conflicts negatively influences the personal image of some teachers, and even creates isolation for some of them; also create demotivation and lack of interest for the school issues, nervousness, and an unfriendly atmosphere in the teachers room, manifestation of professional vanity etc?

Table 3 portrays that $85 \%$ of the respondents acknowledged that conflicts generated by subject allocation to teacher trainers can be locally resolved. This high percentage gives hope that the conflicts generated by the allocation of subjects to teacher trainers are being amicably resolved at the level of the schools. But the worries here are; why conflicts in the first place, how long do they take to be resolved, at what cost are they being 
resolved, how sustainable are the solutions? The ideal situation will be that if people are trained to do a job, giving them the opportunity to exercise their gifts, skills and talents should not face any resistance but should rather be a source of joy and satisfaction. This brings the researcher to the point of questioning whether the teacher trainers were well selected and well trained for the teaching profession ahead of them. It would appear the selection criteria falls short of some standards and or the training falls short of some reference point or rationale. Even though they reported that the conflicts were being locally resolved, they were however living in an inwardly tense state. This is not a very good psychological state as it can play negatively on the teachers' output. This view is supported by Reuben and Sifiso, 2016 who reported that teachers in Gwanda urban and peri urban secondary schools were not happy with the way conflicts were being handled in the school.

Abdul put forth similar findings as follows Conflict is an essential and unavoidable human phenomenon because where there is human interaction; there is a likelihood of personal likes and dislikes. These agreements and disagreements among individuals and groups lead them to conflicts. Conflicts are neither constructive nor disruptive but the ways these are handled make them either positive or negative. Schools, like other human organizations, are prone to one or other type of conflict. Various conflict management strategies are adopted for handling conflict; the most important among these are mediation, negotiation, avoidance, collaborating etc

\subsection{Conclusion}

This study had as purpose to find out the effectiveness of the model of subject allocation of teacher trainers at the GTTC in Cameroon. Specifically it found out if every teacher trainer could effectively teach all subjects of the teacher training programme? Find out the extent to which subjects allocation to teacher trainers are generating conflicts within the school? Find out how conflicts generated by subject allocation to teacher trainers are being resolved? The findings from this study revealed that the belief that every graduate from the Department of Science of Education can effectively teach any subject at the GTTC is purely an illusion. Hence subject allocation to teacher trainers at the GTTC largely lead to conflicts between some of the teacher trainers and Deans of study. Although in most cases these conflicts are being amicably resolved at the level of the schools, they should have an adverse effect on the smooth functioning of the GTTCs. This is by no doubt affecting the output of the teachers and administrators which will in turn adversely affect the performance of the student teachers at the GTTCs. This is telling us that the teacher trainers are not super teachers who can effectively teach a range of subjects (27). There is therefore a need for subject specialisation at the teacher training colleges.

In a similar study, Obert, 2002 carried a study on subject specialisation by teachers in the primary school, as a possible alternative to the conventional approach where one teacher teaches all subjects to a class. The study resulted from the observation that, in spite of mounting evidence suggesting the need for primary school teachers to specialise in one or two subjects only, little was being done along these lines, in Zimbabwe and in most countries the world over. Nine teams in two rural schools, three urban former Group B (formerly for blacks before independence) and three urban former Group A schools (formerly for ' whites before independence) in Zimbabwe, practised subject specialisation (by the teachers) for three school terms and an evaluation was carried out at the end of the three terms: The study sought to find out whether the main stakeholders i.e. pupils, teachers, school heads, and parents would prefer the approach, whether better learning and teaching would result, and the problems and advantages to be met. The findings suggested that the majority of the stakeholders prefer the specialisation approach, and that better learning achievement appeared to accrue. Based on this premise, some recommendations have been made that it is believed if implemented will lead to the eradication of this nuance at the GTTCs. In this same light, Crossfield and Bourne, 2018 noted that despite the fact that the physical environment of the schools appeared healthy and competition for limited resources was rare, intergroup and interpersonal relations were major sources of interpersonal conflict. It was found that management issues, personal practices, work structure, employee development, cultural differences and ethical concerns were major causes of interpersonal conflicts.

Except for the negative impact, some positive impacts of conflict have also been discovered. For example Leung et al. (200) argued that, a suitable level of conflict could stimulate a team's creativity. These ties with the situation whereby the Deans of Study at GBTTC Bafoussam reported they even hire experts from outside the school to train their teachers on some specialized knowledge.

\subsection{Recommendations}

Based on the findings from this study, the following recommendations have been made.

1. To the existing teacher trainers on the field.

They are reminded that with their long academic background they must already developed the skills of lifelong learners. This means with interest they can learn and successfully teach the subjects allocated to them at the GTTCs. They are recommended to learn internet browsing skills that will enable them to be able to search and gather every body of knowledge they need from the internet superhighway.

2. To the Board of Managers of the HTTCs in Cameroon. 
The entry requirements into the Department of Sciences of Education at the Higher Teacher Training Colleges should be revised. A definite number of places should be allocated that will reflect and effectively meet the demands of the subjects offered at the GTTCs. For example there should be specifications such as Fist degree in Bilingual Letters, Mathematics Education, English Modern Letters, Law, Pure Sciences, Computer studies (ICT), Agriculture Science, and so on. The number of places should be allocated based on the needs expressed by the GTTCs. This will be a sustainable solution to such conflicts.

3. To the Ministers of Basic Education, Secondary Education and Higher Education.

These three ministries need to work in constant and closer synergy in order to better meet the needs of one another. The Ministries of Basic and Secondary Education in this case should communicate their expectations to the Ministry of Higher Education who should train these teacher trainers to meet the needs and aspirations of the Cameroonian society and the world at large. People trained should not be redundant upon completion of training. The Grade one Teacher Training Programme should be formulated to meet the needs of the Primary School Programme. The training programme at the Department of Science of Education should satisfy the exigencies of the Grade one Teacher Training Programme. They seem to be existing in isolation from one another.

This is in line with Dilshad (2010) who stated that the quality of teachers depends on the qualification of teachers and quality of pre- service and in-service teacher education they have acquired. This implies that the competence is based on how effective the teacher was trained in the training school and subsequent continuing training.

\section{References}

Abdul, G. (2019). Conflict in Schools: Its Causes \& Management Strategies. Journal of Managerial Sciences $3(6), 212-227$.

Cain, G. \& Plesis, A. (2017). Exploring perceived sources of conflict among educators in three Eastern Cape Schools. Journal of Education, 70(1).

Catana, L. (2015). Conflicts between Teachers: Causes and Effects. Institute of Educational Sciences (ROMANIA) 1(1), 1-5.

Clement, S., Francis, S., \& Gistered, M . (2021). Understanding the 'Taproot' of Conflicts between Teachers and School Administrators and its emergent 'Bitter Fruits' in Selected Primary Schools of Lusaka, International Journal of Research and Innovation in Sciences 5(6), 169-177.

Crossfield, D \& Bourne, A. P. (2018). Management of Interpersonal Conflict between Principals and Teachers in Selected Secondary Schools in Bermuda, Insights of Anthropology, 2(1), 90-104.

Darling-Hammond, L. (2006). Constructing 21st-Century Teacher Education. Journal of Teacher Education, 57 , 300-314

David, R. J. \& David, G. P. (1996). Law and Borders-the Rise of Law in Cyberspace, Stanford Law Review, 48(1), 1367-1404.

Edwards, D. W., \& Roundtree, G. A. (1981). Assessment of behaviour modification programme for modifying disruptive behaviour of emotionally disturbed adolescent males in a residential facility. Corrective \& Social Psychiatry \& Journal of Behaviour Technology, Methods \& Therapy, 27(4), 171-180.

Endeley, M. N. (2014). Teaching Practice in Cameroon: The Effectiveness of the University of Buea model and implications for quality. Australian Journal of Teacher Education, 39(11), 147-160.

Fisher, R.J.(1997). Interactive conflict resolution. Syracuse University Press : Syracuse, New York.

Fonkeng, G. E. (2007).The History of Education in Cameroon, 1884-2004. Lewiston, The Edwin Mellen Press.

Gray, J. L and Strake, F. A. (1984). Organizational Behavior-Concepts and Applications (3rd Ed.) Columbus Bell and Howell Company.

Hafiz, M. I. Muhammad, D. (2010). Quality Indicators in Teacher Education Programmes. Parkistant Journal of Social Sciences, 30(2), 401-411.

Hassan D. A., Ishtiaq H., Muhammad B. H., Syed U. A. G., \& Qaiser S. (2011). Effectiveness of the Teacher Training Programmes Offered by Institute of Education \& Research, Kohat University of Science \& Technology Kohat (KHYBER PUKHTUNKHWA) PAKISTAN. International Journal of Humanities and Social Science, 1 (16), 305-317.

Hocker, J. L., and W. W. Wilmot. (1985). Interpersonal conflict. Dubuque, Iowa: Wm. C. Brown Publishers.

Jehn, K. A. (1997). To agree or not to agree: The effects of value congruence, individual demographic dissimilarity, and conflict of workgroup outcomes. International Journal of Conflict Management, 8(1).

Karen, A. J. (1997). A Qualitative Analysis of Conflict Types and Dimensions in organisational Groups. Administrative Science Quarterly, 42(3), 530-557.

Korthagen et al. (2006). Analyses 'three cases from different continents'. The IVLOS Institute of Education at Utrecht University, The Netherlands; the Faculty of Education at Queen's University, Canada and at the 
Faculty of Education at Monash University, Australia.

Leung, K., Su, K., \& Morris, M. W. (2001). When is criticism not constructive? The roles of fairness perceptions and dispositional attributions in employee acceptance of critical supervisory feedback. Human Relations, 54, $1155-1187$.

Nayereh, S. (2014). Conflict Management Among Secondary School Students, Procedia-Social and Behavioural Sciences 159(1), 630-635.

Ndawi, O. P. (2002). Sharing Teacher Expertise through Subject Specialisation (in the Primary School [STESS]), ZJER vol. 14, (3)

Plunkett, W. R. and Raymond, F. Attner. (1989). Introduction to Management, Boston: PWs-Kent Publishing.

Reuben, T. \& Sifiso, N. (2016). Strategies of Resolving Conflict Among School Personnels in Urban and PeriUrban Secondary Schools in Gwanda District, Zimbabwe. Journal of Humanities and social Sciences, 21(6), $82-90$.

Sonia, M. L. \& Damien, J. P. (2009). Linking Fisher's (1997) model with business performance, Department of Business Administration, National Chengchi University.

Sweeney, B. \& Caruthers, W. L. (1996). Conflict resolution: History, philosophy, theory and educational applications. School Counselor, 43.

Tambo, I. L. \&Tchombe, T. M. (1997). Cameroon Education Project V: Practices and Models of Teacher Education in Cameroon. Buea, Unpublished World Bank sponsored project.

Tchombe, T. M. (2000). Growth and development of teacher education in Cameroon. In Ndongko, T. M. \& Tambo, L. I. (Eds.) Educational Development in Cameroon 1961-1999: Issues and Perspectives. Nkemnji Global Tech, Platteville.

Tchombe, T. M. (2006). Sciences of education: A necessary conceptual base for educational practices in cultural context. In Tchombe, T. M. \& Fonkoua, P. (Eds.) Professionnalisation et formation des enseignements au Cameroun. Les Cahiers de terroires 01, 51-75.

Thomas, K. \& Pondy, L (1976). Towards and Intent Model of Conflict Management Among Principal Parties, Human Relations, 69(30), 1089-1102.

Tosam , F. J. (1988). Implementing Educational change in Cameroon two case studies in Primary Education, London, Institute of Education. 